Recherches en histoire de l'art, histoire des civilisations, archéologie, anthropologie et muséologie

3 | 2013

Cahiers 3

\title{
Les « Ymagiers » à l'École du Louvre
}

\section{Collectif}

\section{OpenEdition}

Journals

Édition électronique

URL : http://journals.openedition.org/cel/520

DOI : $10.4000 /$ cel.520

ISSN : 2262-208X

Éditeur

École du Louvre

Édition imprimée

Date de publication : 1 octobre 2013

Référence électronique

Collectif, "Les "Ymagiers » à l'École du Louvre », Les Cahiers de l'École du Louvre [En ligne], 3 | 2013, mis en ligne le 01 octobre 2013, consulté le 23 septembre 2020. URL : http://journals.openedition.org/ cel/520 ; DOI : https://doi.org/10.4000/cel.520

\section{(c) (i) (9)}

Les Cahiers de l'École du Louvre sont mis à disposition selon les termes de la licence Creative Commons Attribution - Pas d'Utilisation Commerciale - Pas de Modification 4.0 International. 


\title{
Cahiers de l'École du Louvre recherches en histoire de l'art, histoire des civilisations archéologie, anthropologie et muséologie \\ Numéro 3. Octobre 2013
}

\author{
Les « Ymagiers » à l'École du Louvre
}

Article disponible en ligne à l'adresse :

http://www.ecoledulouvre/revue/numero3octobre2013/Ymagiers.pdf

Pour citer cet article :

«Les « Ymagiers » à I'École du Louvre », Cahiers de I'École du Louvre, Recherches en histoire de l'art, histoire des civilisations, archéologie, anthropologie et muséologie [en ligne] no 3, octobre 2013, p. 82.

Cet article est mis à disposition selon les termes de la Licence Creative Commons Attribution - Pas d'utilisation commerciale - Pas de modification 3.0 non transposé. 


\section{Cahiers de l'École du Louvre recherches en histoire de l'art, histoire des civilisations archéologie, anthropologie et muséologie \\ Numéro 3. Octobre 2013}

Sommaire

\section{Éditorial}

Équipe de recherche p. 1

\section{Dossier: les revues}

Le «GR05 ». Approche de quelques revues du XX $X^{\mathrm{e}}$ siècle Introduction d'Hélène Klein

La présentation des objets africains dans DOCUMENTS (1929-1930), magazine illustré

Coline Bidault

Le conflit renaissant de la figure et de l'abstraction dans Labyrinthe, journal mensuel des Lettres et des Arts (octobre 1944-décembre 1946)

Blandine Delhaye

BROOM: An International Magazine of the Arts (1921-1924):

une revue d'avant-garde américaine

Ambre Gauthier

L'image de la guerre dans L'Élan (1915-1916), un refoulement apparent Hadrien Viraben

\section{Articles}

« John Constable et le statut de l'esquisse »

Conférence du 9 avril 2013 dans le cadre du séminaire doctoral

John Murdoch

«Adieu veau, vache, cochon, couvée... » La boucherie à l'Ancien Empire : croisement des données iconographiques, textuelles et archéologiques

Fanny Hamonic

«L’entreprise patrimoniale de Louis-Joseph GUYOT (1836-1924)

à Dourdan, entre érudition et médiation »

Léda Martines

p. $63-72$

\section{Actualité de la recherche}

«Reconnaissance et médiation d'un patrimoine : vecteurs d'une identité territoriale ?» Journées d'étude de troisième cycle, 14 et 15 juin 2012

Noémie Couillard, Nicolas Navarro, Maylis Nouvellon p. $73-81$

Les « Ymagiers » à l'École du Louvre

Cycle de conférences organisées par l'IRHT .... 


\section{Les « Ymagiers » à l'École du Louvre}

Fondé en 1972, le groupe des «Ymagiers » se proposait à l'origine de réunir quelques chercheurs médiévistes qui, au CNRS, à l'Université et dans les métiers de la conservation, s'intéressaient à « l'étude des documents figurés ». D'abord amicales et informelles, ces réunions prirent un tour plus institutionnel à partir de 1976, lorsqu'elles bénéficièrent de l'hospitalité de l'Institut de recherche et d'histoire des textes, laboratoire propre du CNRS entièrement dédié à l'étude des manuscrits médiévaux. Sous l'impulsion de Gaston Duchet-Suchaux puis de Michel Pastoureau, les «Ymagiers » se spécialisèrent dans les questions d'iconographie médiévale et contribuèrent à mieux faire connaittre cette discipline.

À partir de 1999, une nouvelle équipe, animée par Claudia Rabel et Patricia Stirnemann, a plus largement ouvert les séances, notamment vers le public étudiant, et leur a donné une assise et une périodicité plus stables. Désormais les «Ymagiers» se réunissent cinq fois par an, d'octobre à juin, pour entendre un jeune chercheur ou un étudiant doctorant parler de ses travaux récents ou en cours. Une des cinq séances, toutefois, est réservée à un chercheur plus confirmé qui présente un dossier plus vaste, lié à l'actualité de la recherche. Chaque séance dure environ une heure et demie, l'exposé principal étant suivi d'une discussion générale.

Pendant l'année universitaire 2012-2013, l'École du Louvre a donné l'hospitalité aux cinq séances annuelles des "Ymagiers ». Ce fut une expérience très fructueuse, qui a permis de doubler, voire de tripler le nombre des participants et, surtout, d'attirer un public plus jeune que celui habitué à se déplacer dans les locaux de l'IRHT (Institut de recherche et d'histoire des textes), très éloignés du centre de Paris (40, avenue d'Iéna, 75116). Cela a également permis de renforcer les liens entre nos deux institutions. Nous eûmes successivement le plaisir d'entendre Frédéric Tixier parler du culte et de l'iconographie de sainte Agathe à Catane, au Moyen Âge et à l'époque contemporaine (octobre 2012) ; Claudia d'Alberto, des crucifix en bois dans la Rome du milieu du XIVe siècle (décembre 2012) ; Michel Pastoureau, de l'iconographie et de la symbolique des couleurs dans le célèbre Codex Manesse, copié et peint à Zurich, vers 1300-1310 (février 2013) ; Ambre Villain-Debruyne, des sceaux des villes du Nord de la France et des Pays-Bas aux XII ${ }^{e}$ et XIII ${ }^{e}$ siècles (avril 2013) ; Rémy Cordonnier, de l'exégèse visuelle à propos d'une Bible du milieu du XII ${ }^{e}$ siècle aujourd'hui conservée à Saint-Omer. À chaque fois, le public est venu nombreux et les discussions furent riches et animées. L'expérience sera reconduite en 2013-2014.

Pour remercier l'École de Louvre de son hospitalité, l'Institut de recherche et d'histoire des textes a organisé à l'intention des étudiants de l'École une journée spécialement consacrée aux livres d'heures, best sellers des manuscrits enluminés de la fin du Moyen Âge. Outre les interventions de Claudia Rabel (histoire et iconographie des livres d'heures), Jean-Baptiste Lebigue (liturgie et calendriers), Anne-Françoise Leurquin (textes latins et français) et Hanno Wijsman (héraldique et marques de possession), les étudiants purent prendre connaissance des activités et des différents services et instruments de travail offerts par l'IRHT aux chercheurs médiévistes. Ici aussi l'expérience a été fructueuse. Il faut souhaiter qu'elle soit renouvelée.

\section{Pour citation}

Référence électronique

«Les «Ymagiers » à l'École du Louvre », Cahiers de l'École du Louvre. Recherches en histoire de l'art, histoire des civilisations, archéologie, anthropologie et muséologie [en ligne] $\mathrm{n}^{\circ} 3$, octobre 2013.

URL : http://www.ecoledulouvre.fr/revue/numero3octobre2013/Ymagiers.pdf

\section{(c) creative \\ $\Theta \Theta \circledast$}

